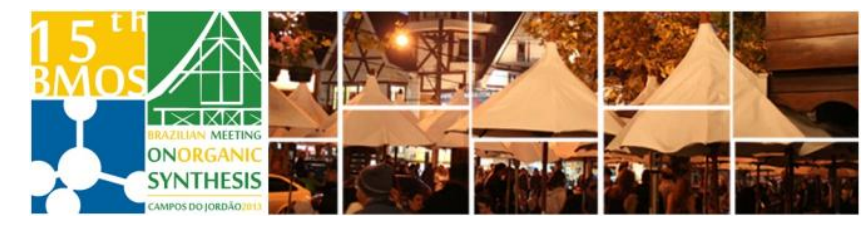

\title{
Study on the intermolecular Enantioselective Heck-Matsuda reaction of acyclic olefin diol
}

\section{Carlise Frota, Caio Costa Oliveira and Carlos R. D. Correia.}

Instituto de Química, Universidade Estadual de Campinas-UNICAMP, R. Josué de Castro s/n. Campinas, São Paulo, Brasil www.correia-group.com

*roque@iqm.unicamp.br

Keywords: Heck-Matsuda, enantioselective catalysis, arylation.

\section{INTRODUCTION}

One of the big challenges in organic chemistry is efficient enantioselective synthesis of acyclic compounds. The palladium-catalyzed coupling between arenediazonium salts and olefins (Heck-Matsuda reaction) represents a robust and accessible method for the synthesis of bioactive and structurally complex molecules. Our group is contributing significantly to the development of the stereo- and enantioselective Heck-Matsuda reaction. In 2013, we described a very practical and efficient method for the enantioselective arylation on acyclic allylic alcohols using commercial chiral bisoxazoline as ligand and several arenediazonium tetrafluoroborates as arylating agents in the presence of palladium trifluoroacetate $\mathrm{Pd}(\mathrm{TFA})_{2} .{ }^{1}$

To further demonstrate the scope and versatility of this method, we describe herein our preliminary results toward the intermolecular enantioselective Heck-Matsuda reaction of acyclic olefins diols with the main goal of synthesizing enantiomerically enriched aryl- $\delta$-lactone as chiral building blocks, which are excellent precursors for the synthesis of bioactive molecules.

\section{RESULTS AND DISCUSSION}

We started preparing our alkene diol 2 by treating 5,6-dihydro-2H-pyran-2-one (1) with 3 equivalents of DIBAL in THF for 3 hours, at $-20^{\circ} \mathrm{C}$. The desired starting alkene diol Z-pent-2-ene-1,5diol (2) was obtained in $72 \%$ yield. (Scheme 1)

Scheme 1 - Synthesis of the starting alkene diol

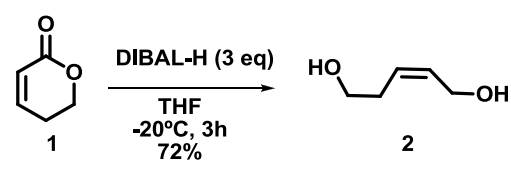

We used our previously developed condition for the enantioselective Heck-Matsuda reaction, obtaining adducts o-methyl-acetals $\mathbf{4}$ and $\mathbf{5}$ with excellent enantiomeric excesses of up to $86 \%$, but with practically no regiocontrol. Without purification, the Heck adducts were submitted to Jones oxidation to provide the symmetric anhydride 6 . On the other hand, hydrolysis followed by oxidation with PCC furnished the desired aryl- $\delta$-lactones in $50 \%$ overall yield as an inseparable mixture.

Scheme 2 - Synthesis of aril- $\delta$-lactone<smiles>[R]C(=O)[C-](C)OC</smiles><smiles>CN1C[C@H](Br)N=C1C1=NC(Br)CO1</smiles>

$\mathrm{Pd}\left(\mathrm{F}_{3} \mathrm{CCO}_{2}\right)_{2}(5 \mathrm{~mol} \%)$ $\mathrm{ZnCO}_{3}(0,5$ eq), $\mathrm{MeOH}$ $60^{\circ} \mathrm{C}, 8$ min.,
$1: 1$

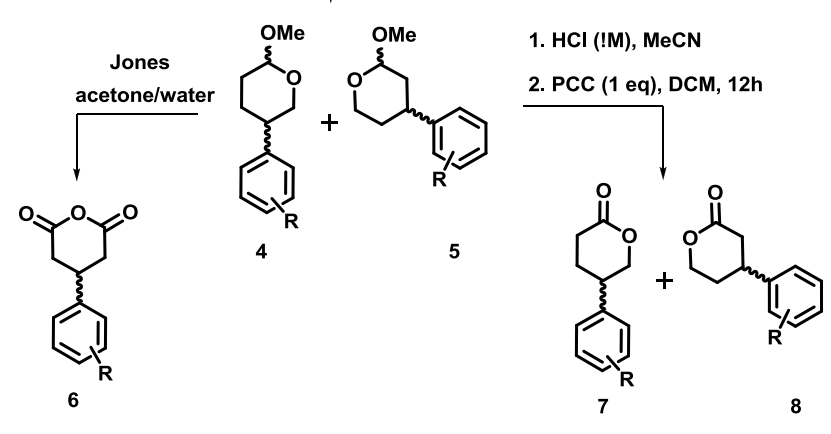

\section{CONCLUSION}

Some initial results demonstrate the feasibility of the enantioselective intermolecular Heck-Matsuda arylation of complex alkene diols. Work is in progress to define the scope of the method and to isolate the corresponding aryl- $\delta$-lactones.

\section{ACKNOWLEDGEMENTS}

We acknowledge FAPESP, CNPq and Capes for financial support and a fellowship.

\section{REFERENCES}

${ }^{1}$ Oliveira, C. C.; Angnes, R. A.; Correia, C. R. D. J. Org. Chem. 2013, 108, 3335. 